\title{
Anomalous origin of the left circumflex coronary artery from the pulmonary artery. A very rare congenital anomaly in an adult patient diagnosed by cardiovascular magnetic resonance Grigorios Korosoglou*, Gerd Ringwald, Evangelos Giannitsis and Hugo A Katus
}

Address: Department of Cardiology, University of Heidelberg, Heidelberg, Germany

Email: Grigorios Korosoglou* - gkorosoglou@hotmail.com; Gerd Ringwald - gerd.ringwald@web.de; Evangelos Giannitsis - evangelos.giannitsis@med.uni-heidelberg.de; Hugo A Katus - hugo.katus@med.uni-heidelberg.de * Corresponding author

Published: 21 january 2008

Journal of Cardiovascular Magnetic Resonance 2008, 10:4 doi:10.1 186/1532-429X-10-4

This article is available from: http://www.jcmr-online.com/content//0/I/4

(c) 2008 Korosoglou et al; licensee BioMed Central Ltd.

This is an Open Access article distributed under the terms of the Creative Commons Attribution License (http://creativecommons.org/licenses/by/2.0), which permits unrestricted use, distribution, and reproduction in any medium, provided the original work is properly cited.
Received: 13 December 2007

Accepted: 21 January 2008

\begin{abstract}
Here we report for the first time on the diagnostic potential of cardiovascular magnetic resonance (CMR) to delineate the proximal course of an anomalous left circumflex coronary artery (LCX) originating from the right pulmonary artery in an adult patient with no other form of congenital heart disease. The patient was referred to our institution due to exertional chest discomfort. XRay coronary angiography showed a normal left anterior descending coronary artery (LAD) and right coronary artery (RCA), while the LCX was filled retrograde by collateral flow through the LAD and the RCA. The origin of the LCX was postulated to be the pulmonary artery, but the exact origin of the anomalous artery could not be depicted on conventional angiograms. CMR provided the unambiguous depiction of the origin of the anomalous LCX from the right pulmonary artery and the delineation of its proximal course in this case of a very rare coronary anomaly in adults.
\end{abstract}

\section{Introduction}

This report describes the anomalous origin of the left circumflex coronary artery (LCX) from the right pulmonary artery (PA) in a 54-year-old woman with no other form of congenital heart disease. Coronary anomalies are a group of congenital disorders with highly variable pathophysiological mechanisms and manifestations. The occurrence of coronary anomalies is $0.3-0.9 \%$ in patients without structural heart disease and significantly higher (3-36\%) in patients with structural heart defects $[1,2]$. Due to the variable clinical presentation and prognosis of coronary anomalies depending on the proximal course of the anomalously arising coronary artery in relation to the great vessels, their early detection, and the exact delineation of their proximal course are crucial $[3,4]$.

\section{Case presentation}

A 54-year-old woman was referred to our institution for routine coronary angiography due to exertional chest discomfort. An exercise ECG by her referring physician was clinically and electrically positive, demonstrating ST-segment depression in leads V5 and V6. Furthermore, nuclear scintigraphy had confirmed the presence of inducible ischemia in the lateral myocardial wall, by showing a reversible perfusion defect in this region during ergometric stress. Coronary angiography showed a normal left anterior descending coronary artery (LAD), while the LCX was filled retrogradely by collateral flow through the LAD (figure 1a). The right coronary artery (RCA) arose in typical position and also provided retrograde filling of the LCX (figure 1b). No evidence of atherosclerotic disease 

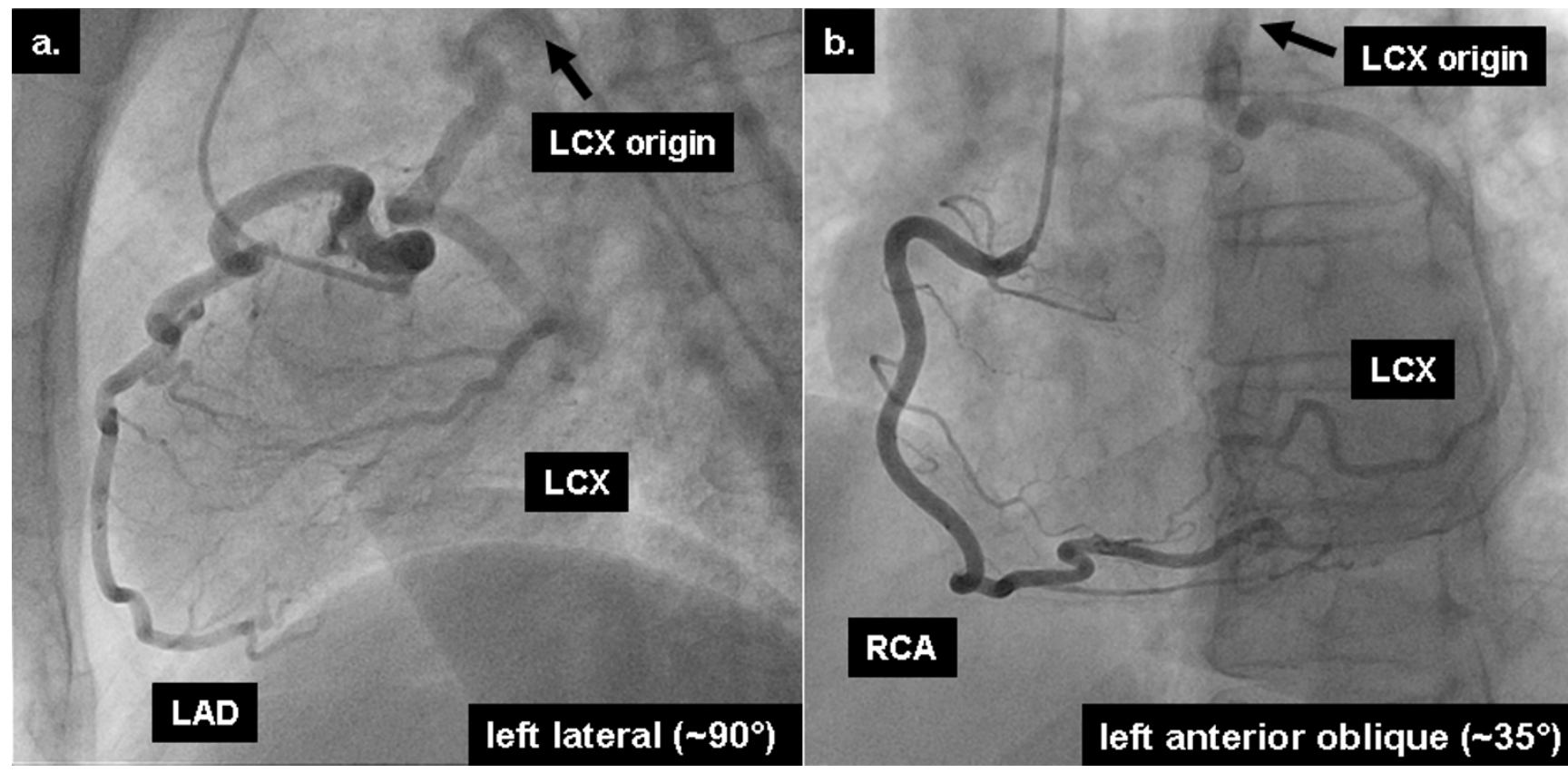

RCA

\section{Figure I}

X-Ray coronary angiography shows the retrograde filling of an anomalous left circumflex artery (LCX) though collateral vessels provided by (a) the left anterior descending artery (LAD) and (b) the right coronary artery (RCA).

was found, either in the left system or in the RCA, and the origin of the LCX (black arrow) was postulated to be the pulmonary artery. To trace the exact anatomical origin of the anomalous LCX, cardiovascular magnetic resonance (CMR) was performed in a clinical 1.5T scanner (Achieva, Philips Medical Systems, Best, The Netherlands). CMR demonstrated normal function of the left ventricle (ejection fraction of $67 \%$ ) and no signs of structural heart disease. Multi-planar reformatted images of $\mathrm{T}_{1}$-weighted, free-breathing, whole-heart acquisitions, allowed the unambiguous delineation of the proximal segments of all 3 coronary arteries. Thus, CMR provided the exact anatomical depiction of the origin of the anomalous LCX (solid arrow, figure 2a) from the right pulmonary artery (hatched arrow, figure 2a) and demonstrated the normal origin of the LAD and RCA (figure 2b). The patient was then referred for cardiac surgery.

\section{Discussion}

In summary, these findings highlight the role of CMR for detecting the exact origin and for delineating the proximal course of anomalous coronary arteries in a case of a very rare coronary anomaly in adults [5-7]. The anomalous origin of the LCX from the pulmonary artery is usually discovered in childhood, and is generally associated with other major congenital cardiac defects, such as patent ductus arteriosus, aortic coarctation, subaortic stenosis and pulmonary valve stenosis $[8,9]$. The presence of an anomalous LCX arising from the pulmonary artery in adults without congenital cardiac defects is very rare. The presentation in adults may be in the form of new-onset exertional angina, shortness of breath, abnormal ischemic changes on ECG or abnormal stress electrocardiography/ nuclear scintigraphy [5-7]. Symptoms and prognosis are usually dependent upon the development of collateral vessels from the two other coronary arteries and the treatment is surgical with either ligation of the LCX at the origin alone, ligation with aorta-coronary bypass or reimplantation of the LCX to the aorta. Although conventional X-Ray angiography has traditionally been used to diagnose coronary anomalies, in some cases the exact orifice of anomalous coronary vessels cannot be selectively identified by this technique $[6,10]$. In our patient the origin of the LCX could not be determined on conventional angiograms and the exact diagnosis was established by the subsequent CMR scan. The three dimensional acquisitions of either CMR or computed tomography (CT) generally allow unambiguous interpretation of the locations of coronary origins. While CT generally offers better spatial resolution, the versatility of CMR can potentially provide additional information on the direction of flow in an anomalous vessel, and information on myocardial viability and perfusion, if required, all without ionizing radiation. However, in case of coronary anomalies coronary angiography should be performed in order to exclude additional atherosclerotic disease. Here we report for the first time on the diagnostic potential of CMR to delineate the proximal course of an anomalous LCX originating 

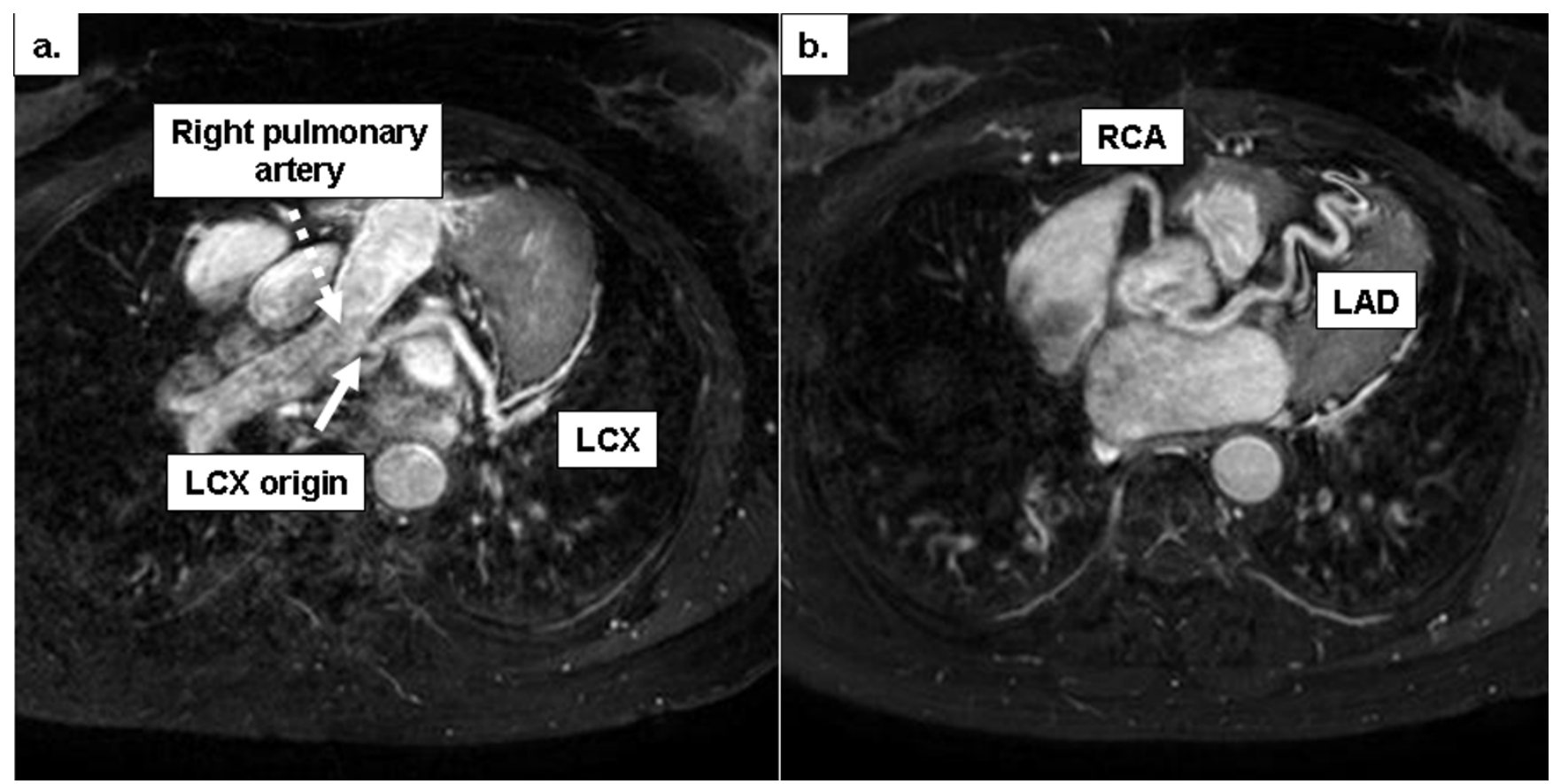

\section{Figure 2}

Multi-planar reformatted CMR images depict the exact origin of (a) the anomalous LCX from the right pulmonary artery and confirm the normal origin and course of $(b)$ the LAD and RCA.

from the right pulmonary artery in an adult patient without structural heart disease.

\section{Competing interests}

The author(s) declare that they have no competing interests.

\section{References}

I. Dabizzi RP, Teodori G, Barletta GA, et al:: Associated coronary and cardiac anomalies in the tetralogy of Fallot. An angiographic study. Eur Heart J 1990, II (8):692-704.

2. Carvalho JS, Silva CM, Rigby ML, et al:: Angiographic diagnosis of anomalous coronary artery in tetralogy of Fallot. $\mathrm{Br}$ Heart $\mathrm{J}$ 1993, 70(I):75-78.

3. Angelini P: Coronary artery anomalies: an entity in search of an identity. Circulation I I ( (10): I 296-1305. Mar I3 2007

4. Gavrielatos G, Letsas KP, Pappas LK, et al.: Anomalous origin of the entire coronary system with separate ostia within the right sinus of valsalva: a rare congenital anomaly and a review of the literature. Cardiology 2007, 107(3):209-2 12.

5. Bolognesi R, Alfieri O, Tsialtas D, et al:: Surgical treatment of the left circumflex coronary artery from the pulmonary artery in an adult patient. Ann Thorac Surg 2003, 75(5): I642-I643.

6. Garcia CM, Chandler J, Russell R: Anomalous left circumflex coronary artery from the right pulmonary artery: first adult case report. Am Heart J 1992, I 23(2):526-528.

7. Gupta S, Malik F, Bertuso J: A rare case of exertional angina in an adult due to anomalous origin of the circumflex artery from the right main pulmonary artery. J Invasive Cardiol 2005, 17(10):EI3-14.

8. Sarioglu T, Kinoglu B, Saltik L, et al.: Anomalous origin of circumflex coronary artery from the right pulmonary artery associated with subaortic stenosis and coarctation of the aorta. Eur J Cardiothorac Surg 1997, I 2(4):663-665.

9. Chopra PS, Reed WH, Wilson AD, et al.: Delayed presentation of anomalous circumflex coronary artery arising from pulmo- nary artery following repair of aortopulmonary window in infancy. Chest 1994, 106(6): 1920-1922.

10. Post JC, van Rossum AC, Bronzwaer JG, et al.: Magnetic resonance angiography of anomalous coronary arteries. A new gold standard for delineating the proximal course? Circulation 92(II):3163-3I7I. Dec I 1995
Publish with Biomed Central and every scientist can read your work free of charge

"BioMed Central will be the most significant development for disseminating the results of biomedical research in our lifetime. "

Sir Paul Nurse, Cancer Research UK

Your research papers will be:

- available free of charge to the entire biomedical community

- peer reviewed and published immediately upon acceptance

- cited in PubMed and archived on PubMed Central

- yours - you keep the copyright
BiolMedcentral 